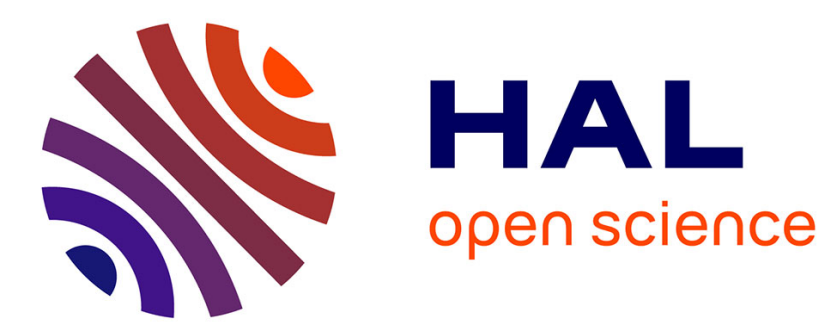

\title{
Co-inoculation of Lolium perenne with Funneliformis mosseae and the dark septate endophyte Cadophora sp. in a trace element-polluted soil
}

Charlotte Berthelot, Damien Blaudez, Thierry Beguiristain, Michel Chalot, Corinne Leyval

\section{To cite this version:}

Charlotte Berthelot, Damien Blaudez, Thierry Beguiristain, Michel Chalot, Corinne Leyval. Coinoculation of Lolium perenne with Funneliformis mosseae and the dark septate endophyte Cadophora sp. in a trace element-polluted soil. Mycorrhiza, 2018, 28 (3), pp.301 - 314. 10.1007/s00572-0180826-z . hal-01930931

\section{HAL Id: hal-01930931 \\ https://hal.science/hal-01930931}

Submitted on 1 Apr 2019

HAL is a multi-disciplinary open access archive for the deposit and dissemination of scientific research documents, whether they are published or not. The documents may come from teaching and research institutions in France or abroad, or from public or private research centers.
L'archive ouverte pluridisciplinaire HAL, est destinée au dépôt et à la diffusion de documents scientifiques de niveau recherche, publiés ou non, émanant des établissements d'enseignement et de recherche français ou étrangers, des laboratoires publics ou privés. 

sp. in a trace element-polluted soil.

Charlotte Berthelot ${ }^{1}$, Damien Blaudez ${ }^{1}$, Thierry Beguiristain ${ }^{1}$, Michel Chalot ${ }^{2,3}$, Corinne Leyval ${ }^{1 \#}$

${ }^{\#}$ Corresponding author: corinne.leyval@univ-lorraine.fr

${ }^{1}$ Université de Lorraine, CNRS, LIEC UMR7360, Faculté des Sciences et Technologies, BP 70239, F-54506 Vandoeuvre-lès-Nancy, France.

${ }^{2}$ Université de Bourgogne Franche-Comté, CNRS, UMR6249 Laboratoire Chrono-Environnement, Pôle Universitaire du Pays de Montbéliard, 4 place Tharradin, BP 71427, F-25211, Montbéliard, France.

${ }^{3}$ Université de Lorraine, Faculté des Sciences et Technologies, BP 70239, F-54506, Vandoeuvre-lès-Nancy, France.

Authors' Orcid numbers:

Berthelot Charlotte: 0000-0002-5452-0242

Blaudez Damien: 0000-0003-3287-3482

Chalot Michel: 0000-0001-8614-0917

Leyval Corinne: 0000-0002-5339-1178 


\begin{abstract}
The presence of dark septate endophytes (DSEs) or arbuscular mycorrhizal fungi (AMF) in plant roots and their effects on plant fitness have been extensively described. However, little is known about their interactions when they are simultaneously colonizing a plant root, especially in trace element (TE)-polluted soils. We therefore investigated the effects of Cadophora sp. and Funneliformis mosseae on ryegrass (Lolium perenne) growth and element uptake in a $\mathrm{Cd} / \mathrm{Zn} / \mathrm{Pb}$-polluted soil. The experiment included four treatments, i.e. inoculation with Cadophora sp., inoculation with F. mosseae, co-inoculation with Cadophora sp. and F. mosseae, and no inoculation. Ryegrass biomass and shoot $\mathrm{Na}, \mathrm{P}, \mathrm{K}, \mathrm{Mg}$ concentrations significantly increased following AMF inoculation as compared to non-inoculated controls. Similarly, DSE inoculation increased shoot Na concentration, whereas dual inoculation significantly decreased shoot $\mathrm{Cd}$ concentration. Moreover, oxidative stress determined by ryegrass leaf malondialdehyde concentration was alleviated both in the AMF and dual inoculation treatments. We used quantitative PCR and microscope observations to quantify colonization rates. They demonstrated that DSEs had no effect on AMF colonization, while AMF colonization slightly decreased DSE frequency. We also monitored fluorescein diacetate (FDA) hydrolysis and alkaline phosphatase (AP) activity in the rhizosphere soils. FDA hydrolysis remained unchanged in the three inoculated treatments, but AMF colonization increased AP activity and P mobility in the soil whereas DSE colonization did not alter AP activity. In this experiment, we unveiled the interactions between two ecologically important fungal groups likely to occur in roots which involved a decrease of oxidative stress and Cd accumulation in shoots. These results open promising perspectives on the fungal-based phytomanagement of TE-contaminated sites by the production of uncontaminated and marketable plant biomass.
\end{abstract}

Keywords: arbuscular mycorrhizal fungi, dark septate endophyte, co-inoculation, Cadophora sp., Funneliformis mosseae, heavy metal pollution 


\section{Introduction}

Intense human activities such as mining, industries, waste disposal, and fertilizer applications have dramatically increased soil contents of trace elements (TE) (Tóth et al. 2016). TE persist in the environment for a long time, and their effects on human health and ecosystems are of great concern. Plants can be used to reduce metal dispersion from TE-contaminated soils into the atmosphere, the soil, and groundwater. Such phytomanagement is economically attractive because it produces nonedible biomass for commercial products such as bioenergy, biofuels, building and construction materials, or timber (Evangelou and Deram 2014). Adapted TE-tolerant soil microorganisms can enhance plant growth and nutrition in such stressed environments (Ma et al. 2011). Among these, arbuscular mycorrhizal fungi (AMF) and dark septate endophytes (DSEs) are abundant root colonists of plants growing in TE-polluted soils.

Dark septate endophytes are sterile or conidial Ascomycetes forming microsclerotia and dark septate hyphae in plant roots. They are abundant in TE-polluted soils (Ruotsalainen et al. 2007; Deram et al. 2011). For instance, Phialophora sp., and Leptodontidium sp. were identified and/or isolated from Chinese and European metal-polluted sites (Ban et al. 2012; Likar and Regvar 2013). Similarly, Cadophora sp. was found in pine roots from a $\mathrm{Zn/Cd}$-polluted site in Belgium and in a TE-polluted soil in Austria (Utmazian et al. 2007; Op De Beeck et al. 2015). In sharp contrast to AMF, ecological functioning of DSEs still is barely understood. There is a paucity of information on DSEs partly because they are difficult to identify because morphological taxonomic traits are scarce (Wang and Wilcox 1985). Moreover, opposite conclusions about their impact on plant fitness have been drawn. Effects of DSEs ranged from pathogenic to neutral or mutualistic relationships depending on fungal strain, plant host and edaphic parameters (Newsham 2011; Mayerhofer et al. 2013; Mandyam and Jumpponen 2015; Berthelot et al. 2017). For instance, in a meta-analysis, Mayerhofer et al. (2013) reported that the plant growth promotion effect of DSEs was higher toward herbs and graminoids than shrubs and trees. In TE-polluted soils, DSEs could promote plant growth and limit metal toxicity to the host by limiting root-to-shoot TE translocation and by increasing chlorophyll concentrations and transpiration rates (Wang et al. 2016; Likar and Regvar 2013). Moreover, DSEs could increase phosphorus concentration in shoots (Barrow and Osuna 2002; Della Monica et al. 2015).

AMF have been extensively studied over the last fifty years, and are considered as essential partners for plant growth and fitness (Göhre and Paszkowski 2006). Arbuscular mycorrhizal fungi (AMF) can be abundant in 
TE-polluted soils (Ruotsalainen et al. 2007; Regvar et al. 2010; Deram et al. 2011). Funneliformis mosseae, Rhizophagus intraradices and Glomus sp. were found abundantly from European, Asian and Canadian As/Cd/Cu/Zn-polluted soils (Weissenhorn et al., 1994; Hassan et al. 2011; Ban et al. 2015; Krishnamoorthy et al. 2015). Likewise, Paraglomerales, and Glomerales such as $R$. irregularis were found dominant in a $\mathrm{Pb} / \mathrm{Zn}-\mathrm{mining}$ site in the south of France (Sánchez-Castro et al. 2017). AMF represent a great potential for remediation of soils contaminated by TE (Göhre and Paszkowski 2006). Several studies have shown that AMF develop mechanisms that allow metal accumulation in plant roots (Redon et al. 2009) and prevent metal translocation to the shoots (Joner and Leyval 1997; Göhre and Paszkowski 2006). In contrast, other studies have shown that AMF cause an increase in metal translocation to shoots (Göhre and Paszkowski 2006). Moreover, AMF affect soil trace and major elements availabilities by inducing mobilization or immobilization processes (White et al. 1997). Specifically, AMF secrete acid and alkaline phosphatases involved in phosphorus mobility and mineralization (Hu et al. 2013). AMF also can induce soil enzyme activities such as $\beta$-glucosidase or dehydrogenase activities (Arriagada et al. 2014).

AMF and DSEs can share the root system of the same plant host (Peyronel 1924; Ruotsalainen et al. 2002; Massenssini et al. 2014) and even the same root zone (Dolinar and Gaberščik, 2010). In the few studies where both AMF and DSE are considered, mainly field studies, their colonization rates were considered. It is not clear from such studies, however, whether interactions between AMF and DSEs were due to relative TE tolerance, competition for space or carbon competition. AMF and DSEs alone were reported as tolerant to TE (Weissenhorn et al., 1994; Ban et al. 2012; Likar and Regvar, 2013). In TE-polluted soils, however, DSEs could sometimes dominate and even replace AMF in the roots of plants. For instance, mycorrhizal colonization of Salix caprea decreased under high metal pollution whereas DSEs colonization was not affected (Regvar et al. 2010). Likewise, DSEs colonization of Arrhenaterum elatius was not impacted by increasing soil Cd concentrations, while AMF colonization decreased (Deram et al. 2011). Similarly, mycorrhizal colonization of Deschampsia flexuosa drastically decreased in TE-polluted soils, whereas colonization by DSEs remained unchanged (Ruotsalainen et al. 2007). Interactions between DSEs and AMF are poorly characterized, but it seems that relationships from competition to synergy could occur (Scervino et al. 2009; Soteras et al. 2013; Della Monica et al. 2015). For instance, the DSE Drechslera sp. produced exudates that stimulated the presymbiotic stage development of AMF on Daucus carota hairy roots in vitro (Scervino et al. 2009). In contrast, colonization of Trifolium repens by Gigaspora rosea was associated with a decreased density of Phialocephala turiciensis (Della Monica et al. 2015). 
Interactions between AMF and DSEs can be studied through the localization and quantification of root colonization by both fungi in the same host plant (Vaz et al. 2012; Saravesi et al. 2014; Della Monica et al. 2015). Microscopic observation of stained roots is laborious, however, and results differ among investigators (Tellenbach et al. 2010). Chemical methods that quantify specific biomolecules stored inside fungal cells or are released into the environment (e.g. ergosterol or chitin) also are widely used (Olsrud and Michelsen 2007). Other methods have been developed, e.g. based on iso-enzymes or antibodies, transformed fungi expressing labeled proteins, or the FISH technique (Wright 2000; Su et al. 2013; Vági et al. 2014). Nevertheless, all these techniques have a low specificity, and may not be adapted to differentiate AMF from DSEs colonizing the same plant tissue (Vági et al. 2014). Quantitative real-time PCR (qPCR) combines specificity at different taxonomic levels with accurate measurements of DNA copy numbers that make it possible to quantify DNA in very small samples. It therefore appeared to us to be a more reliable approach than microscopic observations. qPCR has been successfully applied to quantify phytopathogen (Maciá-Vicente et al. 2009), mycorrhiza (Thonar et al. 2012), or DSEs (Tellenbach et al. 2010) colonization rates. To our knowledge, however, no study has ever quantified AMF and DSEs simultaneously on a single root sample by qPCR.

With the objective to understand interactions between the poorly understood DSEs and the well-known AMF, we investigated the impact of dual inoculation with an AMF (F. mosseae) and a DSE (Cadophora sp.) and their interaction on L. perenne grown in a TE-polluted soil. These two TE-tolerant fungi were isolated from poplar roots growing on TE-polluted soils (Berthelot et al. 2016). We previously reported their ability to promote the growth of different plants such as Populus tremula x alba, Betula pendula and especially $L$. perenne, in TE- or in non-TE-polluted substrates (Berthelot et al. 2016; Berthelot et al. 2017). On the basis of known information we hypothesized that these two strains could co-colonize L. perenne roots and act in synergy to improve its tolerance to $\mathrm{TE}$, improve nutrient acquisition, alleviate stress and result in a positive host growth response. To test this hypothesis, we evaluated AMF and DSE colonization after two months of plant growth, using root staining and qPCR. Plant dry weight, leaf concentrations of total chlorophyll, malondialdehyde (MDA), total antioxidant compounds (TACs), and shoot and soil elemental composition were measured. We also measured phosphatase activity and fluorescein diacetate hydrolysis as indicators of rhizosphere enzymc activity. 


\section{Materials and methods}

\section{Soil physico-chemical properties}

The soil used in the present study was collected at the experimental site of Pierrelaye (Val d'Oise - France; N $49^{\circ} 1^{\prime} 21^{\prime \prime}$ E $\left.2^{\circ} 9^{\prime} 1^{\prime \prime}\right)$. This site is located on a former agricultural plain that was irrigated with non-treated waters from the city of Paris for almost one century. As a result, the topsoil grew contaminated mostly by $\mathrm{Cd}, \mathrm{Pb}$, and $\mathrm{Zn}$ (Table 1). Values observed in this soil were four to six times higher than in local reference agricultural soils as reported by Lamy et al. (2006). The overall characteristics of the site have been provided previously (Lacercat et al., 2016; Foulon et al., 2016). The physico-chemical characterization of the soil (Table 1) was performed by the SADEF laboratory (Aspach-le-bas, France) (COFRAC certificate $\mathrm{N}^{\circ} 1-0751$ ). The $\mathrm{pH}$ and the total carbonate concentration were measured according to the NF ISO 10390 and NF ISO 10693 standards, respectively. Total and $\mathrm{CaCl}_{2}$-extractable metal concentrations were determined by ICP-AES (Varian 720 ES, Raleigh, USA) using the standards ISO 14869 and NEN 5704, respectively. The granulometric analysis was carried out according to the X 317-107 standard through the dispersion of mineral particles after the destruction of organic matter by hydrogen peroxide and the separation of the different classes of particles through sedimentation (particles $<50 \mu \mathrm{m}$ ) and sieving (particles $>50 \mu \mathrm{m}$ ). Organic carbon was determined by sulfochromic oxidation according to the NF ISO 14235 standard. Total nitrogen was determined after mineralization with sulfuric acid according to the NF ISO 11261 standard. Available phosphorus was measured after addition of ammonium oxalate $0.1 \mathrm{M}$ according to the Joret-Hebert method (NF X31-161). Cation exchange capacity (CEC) was measured after percolation of ammonium acetate (1M) at pH 7 (standard NF X31$130)$.

\section{Preparation of AMF and DSE inocula}

The AMF strain Funneliformis mosseae was previously isolated from the TE-polluted Pierrelaye site (Foulon et al. 2016). The AMF inoculum consisted of perlite mixed with a suspension of purified spores harvested from AMF-inoculated hairy root cultures of Daucus carota. The DSE strain was Cadophora sp. Fe06 (Ascomycota, Helotiales) isolated from a TE-polluted site in the north of France (for details see Berthelot et al. 2016). The DSE inoculum was prepared by aseptically growing Fe06 in flasks containing $500 \mathrm{ml}$ of perlite moistened with $250 \mathrm{ml}$ of malt extract medium, according to the method of Likar \& Regvar (2013). The inoculated flasks were incubated at $24{ }^{\circ} \mathrm{C}$ in the dark for 2 weeks. They were manually shaken twice a week to allow homogeneous fungal growth in the substrate. Controls contained perlite with fungus-free agar plugs (mock controls). 


\section{Greenhouse experiment}

The TE-contaminated soil was sterilized by three successive autoclaving steps $\left(120^{\circ} \mathrm{C}\right.$ for 20 min, 2-day intervals between each step). In order to work with a soil only devoid of the fungal microflora, the natural bacterial microflora was re-introduced after soil sterilization. The following procedure was used to reintroduce the native bacterial microflora into the sterilized soil. Non-sterilized soil (125 g) was mixed with $250 \mathrm{ml}$ of $0.9 \%$ $\mathrm{NaCl}$ solution and shaken for 2 hrs. The suspension was subsequently filtered through a 5- $\mu$ m diameter nylon mesh to remove soil particles and fungal propagules. Two hundred and twenty-five grams of sterilized soil were added in 300-ml pots together with $25 \mathrm{~g}$ of fungal inoculum. Two $\mathrm{ml}$ of soil suspension were added per pot. Ryegrass seeds were surface-sterilized (5 min in 70\% (v/v) ethanol; $20 \mathrm{~min}$ in $5 \%(\mathrm{v} / \mathrm{v}) \mathrm{NaClO}$ ) and carefully rinsed 5 times in sterile distilled water. Thirty seeds were sown per pot. After one week of growth, 20 plants were kept per pot. Plants were inoculated with F. mosseae, or with Cadophora sp, or with both fungi, or left not inoculated. DSE treatment consisted of the DSE-perlite inoculum described above, while the AMF treatment consisted of perlite containing 300 spores of $F$. mosseae per pot. The AMF+DSE treatment consisted of $25 \mathrm{~g}$ of the DSE inoculum with the AMF spore suspension added. The control treatment consisted of fungus-free (enriched agar plugs) perlite. Nine replicates per treatment were grown for two months before harvest. The rhizosphere soil was kept at $4{ }^{\circ} \mathrm{C}$ to assess enzymatic activities as described below. The roots and shoots were harvested, weighed and washed with distilled water. Twenty percent of randomly selected roots were analyzed for fungal colonization whereas the remaining roots were dried at $60^{\circ} \mathrm{C}$ for 2 days and weighed. Shoots were divided into three parts. The first part was directly processed for determining chlorophyll concentrations. The second part was crushed with liquid nitrogen and immediately stored at $-80^{\circ} \mathrm{C}$ until its use for quantifying malondialdehyde (MDA) and total antioxidant compounds (TAC). Finally, the remaining part of the shoots was dried at $60^{\circ} \mathrm{C}$ for 2 days, weighed, and analyzed for TE concentrations.

\section{Quantification of shoot elemental concentrations}

Dried shoots were ground to powder in a mortar with liquid nitrogen to measure trace and major element concentrations. For elemental analyses, the powder was digested by $\mathrm{HNO}_{3}$ in a MARS 5 microwave oven (SEM, Saclay, France) for $15 \mathrm{~min}$ at $170{ }^{\circ} \mathrm{C}$ and 20 bars followed by $30 \mathrm{~min}$ cooling. The solutions were analyzed by ICP-AES (Varian 720 ES, Raleigh, USA). Two tobacco (OBTL5, ichtj, Warlow, Poland) and ryegrass (CD281 O204, ERM ${ }^{\circledR}$, Geel, Belgium) standard references were submitted to the same digestion procedure and analyzed 
as part of the quality control of the protocol. Total nitrogen concentrations were analyzed using a CHNS analyzer (FlashEA 1112, ThermoFisher Scientific, Whaltham, USA). One mg per sample was heated at $940^{\circ} \mathrm{C}$ and analyzed. A standard reference (birch leaves; B2166; elemental microanalysis) was used and analyzed identically.

\section{Quantification of chlorophyll, malondialdehyde and total antioxidant compounds}

Chlorophyll concentrations were measured according to the procedure of Ni et al. (2009). Briefly, the pigments were extracted with $5 \mathrm{ml}$ of $80 \%$ acetone from $300 \mathrm{mg}$ of fresh shoots, and chlorophyll concentrations were measured using spectrophotometric absorbance at 645 and $663 \mathrm{~nm}$. Acetone (80\%) was used as a blank. Additionally, MDA and TAC concentrations were measured from $10 \mathrm{mg}$ of frozen leaf tissues of six randomly selected plants per treatment using commercial kits (MAK085 and MAK187, Sigma-Aldrich, Saint-Quentin Fallavier, France) according to the manufacturer's protocols, and each sample analysis was repeated three times.

\section{Evaluation of root colonization by microscopy}

To quantify root colonization by fungi, the roots were stained with trypan blue and observed under an optical microscope, as previously described by Koske and Gemma (1989). Overall, 30 root fragments of $1 \mathrm{~cm}$ were analyzed per sample. Non-septate hyphae with vesicles and arbuscules were counted as AMF, whereas inter/intracellular melanized hyphae and microsclerotia were recorded as DSE. The frequency of root colonization $\left(\mathrm{F}_{\mathrm{DSE}} \%\right.$ and $\mathrm{F}_{\mathrm{AMF}} \%$ ), the intensity of cortex colonization $(\mathrm{H} \%$ and $\mathrm{M} \%$, for DSE and $\mathrm{AMF}$, respectively), and the density of root specific structures (arbuscules (A\%) from F. mosseae, and microsclerotia (MS\%) from Cadophora sp.) were calculated as previously described (Trouvelot et al. 1986; Likar and Regvar 2009). Briefly, intensity of cortex colonization was based on a five-class system ranking: rare (n1; 1\%), low (n2; 1-10\%), medium (n3; 11-50\%); high (n4; 51-90\%); abundant (n5; 91-100\%). Moreover a three-class system was used, which allowed the calculation of $\mathrm{A} \%$ and $\mathrm{MS} \%$ : low (A1; 10\%), medium (A2; 50\%), and high (A3; $\sim 100 \%$ ) number.

$$
F \%=((30-n o) / 30) * 100
$$

where $n o$ is the number of fragments without colonization by DSE $\left(\mathrm{F}_{\mathrm{DSE}} \%\right)$ or $\mathrm{AMF}\left(\mathrm{F}_{\mathrm{AMF}} \%\right)$

$$
H \%(\text { or } M \%)=\frac{95 n 5+70 n 4+30 n 3+5 n 2+n 1}{30}
$$

where $n 5, n 4, n 3, n 2$ and $n 1$ are numbers of root fragments for each of the indices of ranking of root fragments. 


$$
A \%(\text { or } M S \%)=\frac{a * M(\text { or } H)}{100}
$$

where $a=\frac{100 A 3+50 A 2+10 A 1}{100}$

Roots also were analyzed by confocal laser microscopy. Selected root segments first were cut into pieces of 5-10 $\mathrm{mm}$ in length and were labeled with $5 \mu \mathrm{g} \mathrm{ml}^{-1} \mathrm{WGA}{ }^{\circledR} 488$ (Invitrogen, Carlsbad, USA) for 10 min to visualize fungal structures. The autofluorescence of root cell walls was detected between $420 \mathrm{~nm}$ and $470 \mathrm{~nm}$ after UV laser irradiation at $405 \mathrm{~nm}$. An argon laser was used to excite Alexa Fluor ${ }^{\circledR} 488$ dye, and fluorescence was detected between 500 and $550 \mathrm{~nm}$. Image stacks were obtained using a Nikon eclipse TE2000U equipped with a confocal scanner head (AGR-3Q-BLD, Rainbow, Radiance Biorad, Hercules, USA) and a plan APOx20/0.75 objective. All samples were scanned at an x/y scanning resolution of 1024 x 1024 pixels; the z direction step size was $1.5 \mu \mathrm{m}$. The image stacks were visualized and processed using the software program Image J (v.1.43u). The two detection channels of plant and fungal cell fluorescence were assigned differently using RGB color tables to discriminate between the fungal (DSE \& AMF) cells (in green) and the plant cells (in red).

\section{Quantification of DSE and AMF biomass in roots by real-time PCR}

We designed primers and molecular probes to detect Cadophora sp. by real-time PCR. Several Cadophora ITS region sequences obtained from NCBI were aligned using the Clustal W multiple alignment tool, and optimized manually. The primers designed for the DSE strain were Cado-F: 5'CCTTGAATAAATTACCTTTGTTGCTTTGG-3' and Cado-R: 5'-CCTCTGGCGGGCACTCA-3', and amplified a 78-bp fragment. The probe was Cado-P: 5'-FAM-CCGCCTCGTGCCAGTGGC-BHQ1-3'). For F. mosseae, the primers were obtained from Thonar et al. (2012); they amplified a 122-bp fragment from the 28S region (AM-F: 5'-GGAAACGATTGAAGTCAGTCATACCAA-3'; $\quad$ AM-R: $\quad$ 5'CGAAAAAGTACACCAAGAGATCCCAAT-3'); the probe was AM-P: 5'-FAMAGAGTTTCAAAGCCTTCGGATTCGC-BHQ1-3'. The resulting two sets of specific markers (i.e. primers and probes) for the different fungi were subjected to cross-specificity tests by PCR with pure Cadophora sp. Fe06 and F. mosseae genomic DNA (Fig S1).

Genomic DNA from ryegrass axenically cultured on water agar plates and from purified spores of the two fungi from cultures was extracted from $100 \mathrm{mg}$ of fresh material using a DNeasy plant mini kit (Qiagen, Basel, Switzerland) following the manufacturer's recommendations. Ryegrass roots harvested from the soil were processed identically. All samples were normalized at the same DNA concentration. 
Real-time PCR was performed with the iTaq ${ }^{\mathrm{TM}}$ universal probes supermix kit (Biorad, Hercules, USA) in a CFX 96 thermal cycler (Biorad) following the manufacturer's protocol. For each sample, DNA was amplified in a total volume of $20 \mu \mathrm{l}$ containing $10 \mu \mathrm{l}$ of iTaq supermix buffer, $0.5 \mu \mathrm{M}$ of each primer (Cado-F/Cado-R or AMF/AM-R), $0.2 \mu \mathrm{M}$ of molecular beacon probe (Cado-P or AM-P), and $1 \mathrm{ng}$ of DNA template. Amplifications were performed using the following steps: an initial denaturation step at $94^{\circ} \mathrm{C}$ for $3 \mathrm{~min}$, and then 40 cycles of denaturation at $94^{\circ} \mathrm{C}$ for $15 \mathrm{~s}$, annealing at $60^{\circ} \mathrm{C}$ for $20 \mathrm{~s}$, and extension at $72^{\circ} \mathrm{C}$ for $20 \mathrm{~s}$. For each treatment, six randomly selected root samples were studied, with three technical replicates per sample.

\section{Enzyme activity assays}

The activity levels of two hydrolytic enzymes from the soil were measured. Alkaline phosphatase (AP) is involved in the $\mathrm{P}$ cycle, whereas fluorescein diacetate hydrolysis (FDA) results from global activity involving ubiquitous esterase, lipase and protease (Schnurer and Rosswall 1982; Green et al. 2006). The levels of enzymatic activities were evaluated according to previous studies (Marx et al. 2001; Green et al. 2006). Briefly, $2.5 \mathrm{~g}$ of fresh soil were suspended in FDA or AP buffer for 10 min using an orbital shaker (Stuart Scientific SI50), and then sonicated for $120 \mathrm{sec}$. The FDA buffer contained potassium phosphate $(60 \mathrm{mM})$ at $\mathrm{pH}$ 7.6. The AP buffer was made of $100 \mathrm{mM} \mathrm{Na}_{2} \mathrm{HPO}_{4} / \mathrm{KH}_{2} \mathrm{PO}_{4}$ at $\mathrm{pH}$ 7.5. Then, $50-\mu 1$ aliquots were dispensed into 96-well microplates, with 3 technical replicates per sample. Finally, the substrates of the FDA (fluorescein $\left[3^{\prime}, 6\right.$ 'diacetylfluorescein]) or AP (4-methylumbelliferylphosphate) solutions were added to reach a final volume of $200 \mu 1$. The microplates were stored at $28^{\circ} \mathrm{C}$ in the dark, and measurements were done at 60 -min intervals for $6 \mathrm{~h}$. Fluorescence was measured with a spectrophotometer (Safas Xenius XC, Monaco) with adapted wavelengths (523 and $450 \mathrm{~nm}$ for emission; $490 \mathrm{~nm}$ and $330 \mathrm{~nm}$ for excitation for FDA and AP, respectively) and was compared to the values of respective standard curves obtained by diluting fluorescein or 4-methylumbelliferon.

\section{Data analyses}

Normality of data was tested using a Shapiro-Wilk test while homoscedasticity was tested using a Fisher test. Because both conditions were rejected, most data were subsequently analyzed using one-way non-parametric Kruskal-Wallis tests followed by Wilcoxon post hoc tests. Two-way ANOVA were used to study the interactions for different parameters of root colonization. Pearson correlation coefficients were used to determine relationships between (i) qPCR and microscopy analyses, (ii) root colonization and concentration of TE in shoots and (iii) root colonization and soil enzyme activities. The rejection level was set at $\alpha=0.05$ in all analyses. All analyses were performed using R software (version 3.1.3). All reported values are means \pm 
standard errors (SEs). For percentage values we used the arcsine of the square root of the data for statistical analyses.

\section{Results}

\section{Root colonization by F. mosseae and Cadophora sp.}

The AMF strain Funneliformis mosseae and the DSE strain Cadophora sp. Fe06 successfully colonized ryegrass roots, as shown by microscope (Fig 1a, b, Fig 2) and qPCR (Fig 1c, d) analyses. Trypan blue and fluorescence staining of ryegrass root samples showed that Cadophora sp. Fe06 formed typical brain-like (Fig 2a), fully packed (Fig 2c), and loosely packed (Fig 2d) microsclerotia. In cortical and epidermal ryegrass root cells colonized by F. mosseae, arbuscules (Fig 2b) and vesicles (data not shown) were observed. In contrast to the AMF structures that were easily stained blue, hyphae and microsclerotia of the DSE fungus were recalcitrant to trypan blue staining. Moreover, blue-stained hyphae were not septate, whereas brown-stained hyphae were septate, confirming that blue staining was restricted to the AMF. We therefore took advantage of this difference to discriminate root colonization by AMF or DSE hyphae, and determined the frequency and colonization rates of the two colonists. In the AMF+DSE treatment, the presence of Cadophora sp. Fe06 did not affect F. mosseae colonization frequency $\left(\mathrm{F}_{\mathrm{AMF}} \%\right)$ or intensity $(\mathrm{M} \%)$, or the proportion of $F$. mosseae arbuscules (A\%) (Fig 1a) or vesicles (data not shown). Colonization frequency of roots by Cadophora sp. (F $\mathrm{F}_{\mathrm{DSE}} \%$ ), however, was significantly diminished $(39.9 \pm 3.1 \%$, vs. $55.4 \pm 2.5 \%$ under single DSE inoculation), while colonization intensity by hyphae $(\mathrm{H} \%)$ or microsclerotia $(\mathrm{MS} \%)$ were not significantly affected (Fig. 1b).

qPCR analyses confirmed that root colonization by the AMF fungus was not affected by co-inoculation with the DSE. The $28 \mathrm{~S}$ copy numbers from the single and dual inoculation treatments did not differ significantly (Fig 1c). Conversely, ITS copy numbers were significantly lower in the root samples colonized by both fungi than in the DSE-inoculated samples (Fig 1d). Pearson correlation analyses indicated a significant correlation between ITS gene copy numbers and $\mathrm{F}_{\mathrm{DSE}} \%(P<0.001, \mathrm{r}=0.66)$ or $\mathrm{H} \%(P<0.001, \mathrm{r}=0.60)$. Similarly, there was a significant correlation between $28 \mathrm{~S}$ rDNA gene copy numbers and $\mathrm{F}_{\mathrm{AMF}} \%(P<0.001, \mathrm{r}=0.72)$ or $\mathrm{M} \%(P=$ $0.02, \mathrm{r}=0.22)$.

\section{Effect of fungi on plant growth and physiological parameters}

Ryegrass shoot and root dry weights were evaluated after two months of growth (Fig 3a). Total dry weight was significantly promoted by $63.7 \%$ when F. mosseae alone was inoculated, whereas inoculations with Cadophora 
sp. alone or with AMF+DSE did not alter shoot or root dry weight relative to the uninoculated control (Fig 3a). Using two-way ANOVA, we also examined whether the treatments interacted on the different colonization parameters $(\mathrm{F} \%, \mathrm{H} \%, \mathrm{MS} \%$ or $\mathrm{A} \%)$ and plant growth; the analyses revealed no significant effects (data not shown).

The chlorophyll concentration reached the highest values in response to AMF or DSE inoculation as well as AMF+DSE inoculation, but they were not statistically different from the control (Fig 3b). the shoot MDA concentrations of the AMF and AMF+DSE treatments, however, were significantly lower than in the control plants (Fig 3c). The TAC concentration was lower in the AMF+DSE-inoculated plants than in the other three treatments (Fig 3d).

\section{Shoot and soil elemental concentrations}

Shoot concentrations of trace and major elements are shown in Table 2. Whatever the treatment, there was no significant difference in shoot $\mathrm{Cu}, \mathrm{Fe}, \mathrm{Mn}$ (data not shown), or $\mathrm{Zn}$ (Table 2) concentrations. Total shoot $\mathrm{N}$, which ranged from $0.30 \pm 0.07 \%(\mathrm{w} / \mathrm{w})$ for AMF+DSE inoculation to $0.39 \pm 0.08 \%$ for the non-inoculated control, was not altered by any of the treatments. Conversely, inoculation with $F$. mosseae significantly increased $\mathrm{P}, \mathrm{Na}$, and $\mathrm{K}$ shoot concentrations as compared to the control or to the Cadophora treatment. Likewise, DSE inoculation significantly increased shoot Na concentrations. When compared to the control treatment, the shoot Cd concentration was significantly lower in co-inoculated plants (Table 2).

The soil $\mathrm{CaCl}_{2}$-extractable concentrations in $\mathrm{Cd}, \mathrm{Mg}, \mathrm{Na}$, and $\mathrm{Zn}$ were unaffected by the treatments (Table 3). In the presence of the $\mathrm{AMF}, \mathrm{CaCl}_{2}$-extractable $\mathrm{K}(25.7 \mathrm{mg} / \mathrm{kg}$ soil $)$ significantly increased in the soil as compared to the non-inoculated treatment $(18.1 \mathrm{mg} / \mathrm{kg}$ soil, Table 3$)$, whereas it decreased in the soil containing DSEinoculated roots. There were no correlations between TE and major element concentrations in shoots or soils on the one hand and AMF and DSE colonization parameters on the other hand (data not shown).

\section{Soil enzymatic activity}

To assess the effect of Cadophora sp. and F. mosseae on soil microbial activity, we measured fluorescein diacetate (FDA) hydrolysis and alkaline phosphatase (AP) activity in the rhizosphere soil. Kruskal-Wallis tests showed no significant effect of DSE, AMF or dual inoculation on FDA hydrolysis (Fig. 4a). Inoculation with $F$. mosseae increased AP activity by $47 \%(1.1 \pm 0.1 \mathrm{mU} / \mathrm{g})$ as compared to the control $(0.7 \pm 0.1 \mathrm{mU} / \mathrm{g})$. 
Conversely, inoculation with Cadophora sp. $(0.9 \pm 0.2 \mathrm{mU} / \mathrm{g})$ or with the two fungi $(0.8 \pm 0.1 \mathrm{mU} / \mathrm{g})$ (Fig 4b) did not significantly alter AP activity. Moreover, there was no correlation between AMF and DSE colonization frequency or intensity and soil enzyme activity (data not shown).

\section{Discussion}

\section{Root colonization by F. mosseae and Cadophora sp.}

We investigated the impact of dual inoculation with the AMF strain Funneliformis mosseae and the DSE strain Cadophora sp. Fe06 on ryegrass (L. perenne) grown in a $\mathrm{Cd} / \mathrm{Pb} / \mathrm{Zn}$-contaminated soil. Except for the noninoculated control, all plants were successfully colonized. The absence of fungal colonization in the control treatment suggests that the soils were efficiently sterilized and free of any endogenous AMF or endophytic propagules. In the case of single AMF or DSE inoculations, only the inoculated fungus was found in roots, whereas both fungi were found in the case of dual inoculation. The AMF formed typical arbuscules and vesicles in ryegrass roots, whereas the DSE fungus formed brain-like, loosely packed or fully-packed microsclerotia. We previously noticed these different types of microsclerotia in roots inoculated with different DSE species (Berthelot et al. 2016). Little information is available, however, on the diversity and function of the different types of microsclerotia (Yu et al. 2001). This point deserves attention in future studies.

In addition to these microscopy observations, we also monitored root colonization by qPCR, which was previously used to quantify root DSEs (Maciá-Vicente et al. 2009; Tellenbach et al. 2010; Su et al. 2013) and AMF (Thonar et al. 2012) colonization although fungi were inoculated separately in those studies. To determine whether the two fungi could be discriminated by this approach, we designed DSE-specific primers and probes that did not cross-react with plant tissues or with AMF. Quantification of 28S and ITS copy numbers by qPCR revealed a positive correlation between hyphal colonization frequency $\left(\mathrm{F}_{\mathrm{DSE}} \%, \mathrm{~F}_{\mathrm{AMF}} \%\right)$ and intensity $(\mathrm{H} \%$ and M\%), determined microscopically. There was no correlation between microscopy quantification of microscletia or arbuscule structures and qPCR quantifications, however, probably because of the low frequency of AMF arbuscule or DSE microsclerotia structures. Additionally, because microsclerotia form tight complexes with thick-walled cells (Tellenbach et al. 2010), DNA extraction was problematic, and this may have impeded amplification. To determine arbuscule abundance in Medicago roots by RT-PCR, Isayenkow et al. (2014) suggested use of the specific mycorrhiza-induced phosphate transporter MtPT4, localized to the periarbuscular 
membrane, as a colonization marker. The use of similar colonization markers to amplify genes that are specific to microsclerotia might provide a useful perspective to improve the monitoring of DSE structures in plant roots. Laser ablation of microsclerotia coupled with transcriptomic analyses could be a strategy to identify such specific gene markers.

Using both molecular and microscopy approaches, we noticed a significant decrease of the frequency of root colonization by Cadophora sp. in dual inoculation with F. mosseae, whereas colonization by $F$. mosseae was not affected by the presence of the DSE. The intensity of root colonization by the DSE (MS\% and H\%), however, was not affected by the presence of the AMF. Thus, our data conflict with the few data published to date. The DSE Dreschlera sp. decreased colonization of Daucus carota hairy roots by Gigaspora rosea in an in vitro approach (Scervino et al. 2009). Similarly, a negative correlation was found between colonization of Polylepis australis roots by an AMF and colonization by a DSE in microscopy analyses (Soteras et al. 2013). The same tendency was recorded for dual inoculation of Trifolium repens roots with Phialocephala turiciensis and G. rosea (Della Monica et al. 2015). This inhibition could be explained by competition for carbon compounds or space or by the production of volatile or soluble secondary metabolites (Calvet et al. 1992; Whipps 2001). Antibiosis and competition for carbon compounds or for space have been shown between fungi colonizing the same plant (Perotto et al. 2013). In our experiment the two fungi were found close to each other, in the same root fragments. This observation suggests that either no competition occurred between the two symbionts, or they were able to overcome or tolerate any interference (antibiosis) or exploitation competition.

\section{Impact of Cadophora sp. and $\mathrm{F}$. mosseae on plant growth}

Inoculation with Cadophora sp. did not affect biomass production as compared to the non-inoculated control, while inoculation with $F$. mosseae increased shoot biomass. Numerous studies have investigated the impact of different F. mosseae strains on plant growth on TE-contaminated soils (Takacs and Voros 2003; Citterio et al. 2005; Chen et al. 2007; Redon et al. 2009; Shahabivand et al. 2012; Hu et al. 2013). Studies on the impact of DSEs on plant growth, however, are scarce. Inoculation of Salix sp., S. caprea and S. smithiana with Cadophora finlandica in TE-polluted soils led to neutral to negative effects on plant growth, and shoot TE concentrations were unaffected (Utmazian et al. 2007; De Maria et al. 2011). On the other hand, birch and poplar grew better on TE-polluted soil as a result of inoculation with Cadophora sp., and their shoot Cd concentration decreased as compared to non-inoculated plants (Berthelot et al. 2017). In the present work, root colonization parameters were not correlated with ryegrass growth. An absence of correlation between colonization rate and plant growth 
promotion has been reported for both DSEs and AMF (Hildebrandt et al. 2007; Berthelot et al. 2016). DSE inoculation did not alter ryegrass growth, suggesting a neutral relationship of the fungus with this plant, but the shoot $\mathrm{Na}$ concentration significantly increased.

In agreement with previous studies (Vaz et al. 2012; Della Monica et al. 2015), we found no antagonistic effect of dual DSE+AMF inoculation on ryegrass growth. Shahabivand et al. (2012) reported that dual inoculation of wheat with F. mosseae and the well-known (non DSE) endophytic fungus Piriformospora indica in TE-polluted soils promoted plant growth. Similarly, eucalypt growth benefited from the interaction between saprotrophic fungi and Rhizophagus irregularis in TE-contaminated sites (Arriagada et al. 2014; Fuentes et al. 2016). But the effect of a consortium of microorganisms on plant growth is usually plant-, microbe-, and environmentdependent (Reininger et al. 2012). For instance, a consortium of AMF and endophyte fungi increased Lolium vulgare growth whereas it decreased Trifolium pratense growth (Rillig et al. 2014).

F. mosseae increased shoot $\mathrm{Na}, \mathrm{K}$, and $\mathrm{P}$ concentrations. Numerous studies have shown that mycorrhizal roots are indeed more efficient in P nutrition than non-mycorrhizal roots (Javot et al. 2007; Smith et al. 2011), and the role of AMF extraradical hyphae in soil-to-plant P transport is acknowledged (Smith et al. 2011; Bagyaraj et al. 2015). For instance, the beneficial impact of root colonization by F. mosseae on Coreopsis drummondii growth on a TE-polluted soil resulted from improved P nutrition of plant tissues (Chen et al. 2007).

Dual inoculation with Cadophora sp. and F. mosseae significantly decreased shoot Cd concentrations. In previous studies, the F. mosseae $\mathrm{P} 2$ strain, isolated from a TE-contaminated soil, was found highly tolerant to TEs and able to reduce $\mathrm{Zn}$ and $\mathrm{Cd}$ transfer to Trifolium subterraneum shoots. This protective effect was attributed to the high metal sorption capacity of the hyphae (Joner and Leyval 1997; Joner et al. 2000). For DSEs, Zhan et al. (2015) showed that Exophiala pisciphila could adsorb 81 to $97 \%$ of Cd onto its cell walls, but none of those previous studies was confirmed in planta or performed with another DSE (such as Cadophora sp.). Nevertheless, a recent work showed that E. pisciphila could decrease plant Cd accumulation by modifying Cd speciation in plant tissues and by down-regulating several plant TE transporters (Wang et al. 2016). Yet we do not know whether these proteins effectively transport $\mathrm{Cd}$ or whether these plant transcriptional changes arise from general regulation of ion homeostasis in response to the DSE fungus and/or to Cd exposure.

TEs are potential inducers of oxidative stress in plant cells that likely promote the generation of reactive oxygen species (ROS) (Schützendübel and Polle 2002). Excessive MDA accumulation in plants is caused by oxidative damage of membrane lipids. In the present experiment, MDA concentrations in AMF or AMF+DSE plants and 
TAC concentrations in $\mathrm{AMF}+\mathrm{DSE}$ plants were significantly lower than in non-inoculated plants. Therefore fungal colonization may have alleviated TE oxidative stress. A similar trend of the MDA concentration was reported for Capsicum annuum inoculated with $F$. mosseae under $\mathrm{Cu}$ stress (Latef et al. 2011), while DSE colonization alone did not alter MDA or TAC concentrations of ryegrass shoots. Contrasting effects of DSEs on MDA and TAC concentrations have been reported in the literature. For instance, colonization of maize by $E$. pisciphila in Cd-polluted soil involved a significant decrease of the shoot MDA concentration (Wang et al. 2016), whereas it did not affect MDA or TAC concentration in another experiment (He et al. 2017). Likewise, the impact of DSEs on shoot MDA concentrations was soil- and plant species-dependent in the presence of Leptodontidium sp. and Phialophora mustea, as suggested by Berthelot et al. (2017).

\section{Impact of Cadophora sp. and F. mosseae inoculation on soil enzyme activity}

To assess the impact of F. mosseae and Cadophora sp. inoculation on rhizosphere enzyme activity, we studied alkaline phosphatase (AP) activity and fluorescein diacetate (FDA) hydrolysis. Inoculation with $F$. mosseae or Cadophora sp. alone or with both fungi did not affect the soil FDA activity as compared to the non-inoculated control. Similarly, AP activity did not differ in the presence of Cadophora sp. in the single or dual inoculation treatments. This result contrasts with the increase in AP activity recorded in the rhizosphere of $T$. repens inoculated with the DSE Phialocephala glaciacis (Della Monica et al. 2015). AP activity increased, however, in the rhizosphere of ryegrass inoculated only with F. mosseae. This increase could be explained as follows: (i) the AMF released metabolites that promoted rhizosphere activity (Azcón-Aguilar and Barea 2015), or (ii) the AMF secreted phosphatases that subsequently increased the total pool of these enzymes in the rhizosphere soil (Liu et al. 2013; Sato et al. 2015). Moreover, F. mosseae inoculation also increased the labile pool of K and the shoot K concentration, as observed previously by Meena et al. (2014) and Dominguez-Nunez et al. (2016).

\section{Conclusions}

Tripartite interactions between DSEs, AMF and plants in TE-polluted soils have received little attention until recently. In the present study, dual inoculation with Cadophora sp. and F. mosseae did not improve ryegrass growth and mineral nutrition, but it induced the alleviation of oxidative stress and a decrease of Cd concentrations in shoots. We could take advantage of these observations to support sustainable production of biomass within the fungal-based phytomanagement of TE-contaminated sites. Producing clean or lowcontaminated biomass in such context could also contribute to minimize TE-transfer to the food chain. 
Nevertheless further experiments will be needed to determine (i) whether other combinations of AMF, DSEs, and plant species could also mimic the present findings and (ii) how such tripartite interactions could be successful in situ.

\section{Acknowledgements}

This work was supported by the LORVER project (www.lorver.org) funded by the Lorraine Region and the European Regional Development Fund (ERDF), and by the Agence Nationale de la Recherche (ANR) under the Blanc International ANR-10-INTB-1703-01-BIOFILTREE project. We would like to thank Christine Friry, David Billet and Philippe Rousselle for technical support in plant growth and TE analyses.

\section{References}

Arriagada C, Almonacid L, Cornejo P, et al (2014) Influence of an organic amendment comprising saprophytic and mycorrhizal fungi on soil quality and growth of Eucalyptus globulus in the presence of sewage sludge contaminated with aluminium. Arch Agron Soil Sci 60:1229-1248. doi: 10.1080/03650340.2013.878455

Azcón-Aguilar C, Barea JM (2015) Nutrient cycling in the mycorrhizosphere. J Soil Sci Plant Nutr 15:372-396. doi: $10.4067 / \mathrm{S} 0718-95162015005000035$

Bagyaraj DJ, Sharma MP, Maiti D (2015) Phosphorus nutrition of crops through arbuscular mycorrhizal fungi. Curr Sci 108:1288-1293.

Ban Y, Tang M, Chen H, et al (2012) The response of dark septate endophytes (DSE) to heavy metals in pure culture. PLoS One 7:e47968. doi: 10.1371/journal.pone.0047968

Ban Y, Xu Z, Zhang H, et al (2015) Soil chemistry properties, translocation of heavy metals, and mycorrhizal fungi associated with six plant species growing on lead-zinc mine tailings. Ann Microbiol 65:503-515. doi: $10.1007 / \mathrm{s} 13213-014-0886-\mathrm{z}$

Barrow JR, Osuna P (2002) Phosphorus solubilization and uptake by dark septate fungi in fourwing saltbush, Atriplex canescens (Pursh) Nutt. J Arid Environ 51:449-459. doi: 10.1006/jare.2001.0925

Berthelot C, Blaudez D, Leyval C (2017) Differential growth promotion of poplar and birch inoculated with three dark septate endophytes in two trace element-contaminated soils. Int J Phytoremediation. doi: 
10.1080/15226514.2017.1328392 (in press).

Berthelot C, Leyval C, Foulon J, et al (2016) Plant growth promotion, metabolite production and metal tolerance of dark septate endophytes isolated from metal-polluted poplar phytomanagement sites. FEMS Microbiol Ecol 92:fiw144. doi: 10.1093/femsec/fiw144

Brundrett M (2004) Diversity and classification of mycorrhizal associations. Biol Rev 79:473-495. doi: $10.1017 / \mathrm{S} 1464793103006316$

Calvet C, Barea JM, Pera J (1992) In vitro interactions between the vesicular-arbuscular mycorrhizal fungus Glomus mosseae and some saprophytic fungi isolated from organic substrates. Soil Biol Biochem 24:775780. doi: 10.1016/0038-0717(92)90252-S

Chen BD, Zhu YG, Duan J, et al (2007) Effects of the arbuscular mycorrhizal fungus Glomus mosseae on growth and metal uptake by four plant species in copper mine tailings. Environ Pollut 147:374-380. doi: 10.1016/j.envpol.2006.04.027

Citterio S, Prato N, Fumagalli P, et al (2005) The arbuscular mycorrhizal fungus Glomus mosseae induces growth and metal accumulation changes in Cannabis sativa L. Chemosphere 59:21-9. doi: 10.1016/j.chemosphere.2004.10.009

De Maria S, Rivelli AR, Kuffner M, et al (2011) Interactions between accumulation of trace elements and macronutrients in Salix caprea after inoculation with rhizosphere microorganisms. Chemosphere 84:12561261. doi: 10.1016/j.chemosphere.2011.05.002

Della Monica IF, Saparrat MCN, Godeas AM, Scervino JM (2015) The co-existence between DSE and AMF symbionts affects plant $\mathrm{P}$ pools through P mineralization and solubilization processes. Fungal Ecol 17:1017. doi: 10.1016/j.funeco.2015.04.004

Deram A, Languereau F, Haluwyn C (2011) Mycorrhizal and endophytic fungal colonization in Arrhenatherum elatius L. roots according to the soil contamination in heavy metals. Soil Sediment Contam 20:114-127. doi: $10.1080 / 15320383.2011 .528470$

Dolinar N, Gaberščik A (2010) Mycorrhizal colonization and growth of Phragmites australis in an intermittent wetland. Aqua Bot 93 :93-98. doi: 10.1016/j.aquabot.2010.03.012

Dominguez-Nunez JA, Benito B, Berrocal-Lobo M, Albanesi A (2016) Mycorrhizal fungi: Role in the solubilization of potassium. In: Meena VS, Maurya BH, Verma JP, Meena RS (eds) Potassium solubilizing 
microorganisms for sustainable agriculture. Springer India, pp 77-98

Evangelou MWH, Deram A (2014) Phytomanagement : A realistic approach to soil remediating phytotechnologies with new challenges for plant science. Int J Plant Bio Res 2:1-4.

Foulon J, Zappelini C, Durand A, et al (2016) Impact of poplar-based phytomanagement on soil properties and microbial communities in a metal- contaminated site. FEMS Microbiol Ecol 92:fiw163. doi: 10.1093/femsec/fiw163

Fuentes A, Almonacid L, Ocampo JA, Arriagada C (2016) Synergistic interactions between a saprophytic fungal consortium and Rhizophagus irregularis alleviate oxidative stress in plants grown in heavy metal contaminated soil. Plant Soil 407:355-366. doi: 10.1007/s11104-016-2893-2

Göhre V, Paszkowski U (2006) Contribution of the arbuscular mycorrhizal symbiosis to heavy metal phytoremediation. Planta 223:1115-22. doi: 10.1007/s00425-006-0225-0

Green VS, Stott DE, Diack M (2006) Assay for fluorescein diacetate hydrolytic activity: Optimization for soil samples. Soil Biol Biochem 38:693-701. doi: 10.1016/j.soilbio.2005.06.020

Hassan SED, Boon E, St-Arnaud M, Hijri M (2011) Molecular biodiversity of arbuscular mycorrhizal fungi in trace metal-polluted soils. Mol Ecol 20:3469-3483. doi: 10.1111/j.1365-294X.2011.05142

Hildebrandt U, Regvar M, Bothe H (2007) Arbuscular mycorrhiza and heavy metal tolerance. Phytochemistry 68:139-146. doi: 10.1016/j.phytochem.2006.09.023

He Y, Yang Z, Li M, et al (2017) Effects of a dark septate endophyte (DSE) on growth, cadmium content, and physiology in maize under cadmium stress. Environ Sci Pollut Res 24:18494-18504. doi: 10.1007/s11356017-9459-6

$\mathrm{Hu}$ J, Wu S, Wu F, et al (2013) Arbuscular mycorrhizal fungi enhance both absorption and stabilization of Cd by Alfred stonecrop (Sedum alfredii Hance) and perennial ryegrass (Lolium perenne L.) in a Cd-contaminated acidic soil. Chemosphere 93:1359-65. doi: 10.1016/j.chemosphere.2013.07.089

Javot H, Pumplin N, Harrison MJ (2007) Phosphate in the arbuscular mycorrhizal symbiosis: Transport properties and regulatory roles. Plant, Cell Environ 30:310-322. doi: 10.1111/j.1365-3040.2006.01617.x

Joner EJ, Briones R, Leyval C (2000) Metal-binding capacity of arbuscular mycorrhizal mycelium. Plant Soil 226:227-234. doi: 10.1023/A:1026565701391 
Joner EJ, Leyval C (1997) Uptake of ${ }^{109} \mathrm{Cd}$ by roots and hyphae of a Glomus mosseae/Trifolium subterraneum mycorrhiza from soil amended with high and low contents of cadmium. New Phytol 135:353-360. doi: 10.1046/j.1469-8137.1997.00633.x

Jumpponen A, Trappe JM (1998) Dark septate endophytes: A review with special reference to facultative biotrophic root-colonizing fungi. New Phytol 140:295-310. doi: 10.1046/j.1469-8137.1998.00265.x

Koske RE, Gemma JN (1989) A modified procedure for staining roots to detect VA mycorrhizas. Mycol Res 92:486-488. doi: 10.1016/S0953-7562(89)80195-9

Krishnamoorthy R, Kim C-G, Subramanian P, et al (2015) Arbuscular mycorrhizal fungi community structure, abundance and species richness changes in soil by different levels of heavy metal and metalloid concentration. PLoS One 10:e0128784. doi: 10.1371/journal.pone.0128784

Lacercat-Didier L, Berthelot C, Errard A, et al (2016) New mutualistic fungal endophytes isolated from poplar roots display high metal tolerance. Mycorrhiza 26:1-15. doi: 10.1007/s00572-016-0699-y

Lamy I, Van Oort F, Dère C, Baize D (2006) Use of major- and trace-element correlation to assess metal migration in sandu luviosols irrigated with wastewater. Eur J Soil Sci 57:731-740. doi: 10.1111/j.13652389.2005.00765.x

Latef A, Arafat H, Chaoxing H (2011) Effect of arbuscular mycorrhizal fungi on growth, mineral nutrition, antioxidant enzymes activity and fruit yield of tomato grown under salinity stress. Sci Hortic (Amsterdam) 127:228-233. doi: 10.1016/j.scienta.2010.09.020

Li T, Liu MJ, Zhang XT, et al (2011) Improved tolerance of maize (Zea mays L.) to heavy metals by colonization of a dark septate endophyte (DSE) Exophiala pisciphila. Sci Total Environ 409:1069-1074. doi: 10.1016/j.scitotenv.2010.12.012

Likar M, Regvar M. (2009) Application of temporal temperature gradient gel electrophoresis for characterisation of fungal endophyte communities of Salix caprea L. in a heavy metal polluted soil. Sci Total Environ 407:6179-6187. doi: 10.1016/j.scitotenv.2009.08.045

Likar M, Regvar M (2013) Isolates of dark septate endophytes reduce metal uptake and improve physiology of Salix caprea L. Plant Soil 370:593-604. doi: 10.1007/s11104-013-1656-6

Liu Q, Parsons AJ, Xue H, et al (2013) Functional characterisation and transcript analysis of an alkaline phosphatase from the arbuscular mycorrhizal fungus Funneliformis mosseae. Fungal Genet Biol 54:52-59. doi: 10.1016/j.fgb.2013.02.009

Ma Y, Prasad MN V, Rajkumar M, Freitas H (2011) Plant growth promoting rhizobacteria and endophytes 
accelerate phytoremediation of metalliferous soils. Biotechnol Adv 29:248-58. doi: 10.1016/j.biotechadv.2010.12.001

Maciá-Vicente JG, Jansson H-B, Talbot NJ, Lopez-Llorca L V. (2009) Real-time PCR quantification and livecell imaging of endophytic colonization of barley (Hordeum vulgare) roots by Fusarium equiseti and Pochonia chlamydosporia. New Phytol 182:213-228. doi: 10.1111/j.1469-8137.2008.02743.x

Mandyam K, Jumpponen A (2005) Seeking the elusive function of the root-colonising dark septate endophytic fungi. Stud Mycol 53:173-189. doi: 10.3114/sim.53.1.173

Mandyam KG, Jumpponen A (2015) Mutualism parasitism paradigm synthesized from results of root-endophyte models. Front Microbiol 5:1-13. doi: 10.3389/fmicb.2014.00776

Marx M, Wood M, Jarvis SC (2001) A microplate fluorimetric assay for the study of enzyme diversity in soils. Soil Biol Biochem 33:1633-1640. doi: 10.1016/S0038-0717(01)00079-7

Mayerhofer MS, Kernaghan G, Harper KA (2013) The effects of fungal root endophytes on plant growth: A meta-analysis. Mycorrhiza 23:119-128. doi: 10.1007/s00572-012-0456-9

Meena VS, Maurya BR, Verma JP (2014) Does a rhizospheric microorganism enhance $\mathrm{K}^{+}$availability in agricultural soils? Microbiol Res 169:337-347. doi: 10.1016/j.micres.2013.09.003

Newsham KK (2011) A meta-analysis of plant responses to dark septate root endophytes. New Phytol 190:78393. doi: 10.1111/j.1469-8137.2010.03611.x

Ni Z, Kim E-D, Ha M, et al (2009) Altered circadian rhythms regulate growth vigour in hybrids and allopolyploids. Nature 457:327-31. doi: 10.1038/nature07523

Olsrud M, Michelsen A (2007) Ergosterol content in ericaceous hair roots correlates with dark septate endophytes but not with ericoid mycorrhizal colonization. Soil Biol Biochem 39:1218-1221. doi: 10.1016/j.soilbio.2006.11.018

Op De Beeck M, Lievens B, Busschaert P, et al (2015) Impact of metal pollution on fungal diversity and community structures. Environ Microbiol 17:2035-47. doi: 10.1111/1462-2920.12547

Peyronel B (1924) Prime ricerche sulla micorizae endotrofiche e sulla microflora radicola normalle della fanerograme. Revista biologica 6:17-53

Perotto S, Angelini P, Bianciotto V, et al (2013) Interactions of fungi with other organisms. Plant Biosyst - An Int J Deal with all Asp Plant Biol 147:208-218. doi: 10.1080/11263504.2012.753136 
Phillips JM, Hayman DS (1970) Improved procedures for clearing roots and staining parasitic and vesiculararbuscular mycorrhizal fungi for rapid assessment of infection. Trans Br Mycol Soc 55:158-161. doi: $10.1016 / \mathrm{S} 0007-1536(70) 80110-3$

Redon PO, Béguiristain T, Leyval C (2009) Differential effects of AM fungal isolates on Medicago truncatula growth and metal uptake in a multimetallic $(\mathrm{Cd}, \mathrm{Zn}, \mathrm{Pb})$ contaminated agricultural soil. Mycorrhiza 19:187-195. doi: 10.1007/s00572-009-0230-9

Regvar M, Likar M, Piltaver A, et al (2010) Fungal community structure under goat willows (Salix caprea L.) growing at metal polluted site: the potential of screening in a model phytostabilisation study. Plant Soil 330:345-356. doi: 10.1007/s11104-009-0207-7

Reininger V, Grunig CR, Sieber TN (2012) Host species and strain combination determine growth reduction of spruce and birch seedlings colonized by root-associated dark septate endophytes. Environ Microbiol 14:1064-1076. doi: 10.1111/j.1462-2920.2011.02686.x

Ruotsalainen AL, Väre H, Vestberg M (2002) Seasonality of root fungal colonization in low-alpine herbs. Mycorrhiza 12:29-36. doi: 10.1007/s00572-001-0145-6

Ruotsalainen AL, Markkola A, Kozlov M V. (2007) Root fungal colonisation in Deschampsia flexuosa: Effects of pollution and neighbouring trees. Environ Pollut 147:723-728. doi: 10.1016/j.envpol.2006.09.004

Sánchez-Castro I, Gianinazzi-Pearson V, Cleyet-Marel JC, et al (2017) Glomeromycota communities survive extreme levels of metal toxicity in an orphan mining site. Sci Total Environ 598:121-128. doi: 10.1016/j.scitotenv.2017.04.084

Saravesi K, Ruotsalainen AL, Cahill JF (2014) Contrasting impacts of defoliation on root colonization by arbuscular mycorrhizal and dark septate endophytic fungi of Medicago sativa. Mycorrhiza 24:239-45. doi: $10.1007 / \mathrm{s} 00572-013-0536-5$

Sato T, Ezawa T, Cheng W, Tawaraya K (2015) Release of acid phosphatase from extraradical hyphae of arbuscular mycorrhizal fungus Rhizophagus clarus. Soil Sci Plant Nutr 61:269-274. doi: $10.1080 / 00380768.2014 .993298$

Scervino JM, Gottlieb A., Silvani V A., et al (2009) Exudates of dark septate endophyte (DSE) modulate the development of the arbuscular mycorrhizal fungus (AMF) Gigaspora rosea. Soil Biol Biochem 41:17531756. doi: 10.1016/j.soilbio.2009.04.021 
Schnurer J, Rosswall T (1982) Fluorescein diacetate hydrolysis as a measure of total microbial activity in soil and litter. Appl Environ Microbiol 43:1256-1261. doi: 0099-2240/82/061256-06\$02.00/0

Schützendübel A, Polle A (2002) Plant responses to abiotic stresses: heavy metal-induced oxidative stress and protection by mycorrhization. J Exp Bot 53:1351-65.

Shahabivand S, Maivan HZ, Goltapeh EM, et al (2012) The effects of root endophyte and arbuscular mycorrhizal fungi on growth and cadmium accumulation in wheat under cadmium toxicity. Plant Physiol Biochem 60:53-8. doi: 10.1016/j.plaphy.2012.07.018

Smith SE, Jakobsen I, Grønlund M, Smith FA (2011) Roles of arbuscular mycorrhizas in plant phosphorus nutrition: interactions between pathways of phosphorus uptake in arbuscular mycorrhizal roots have important implications for understanding and manipulating plant phosphorus acquisition. Plant Physiol 156:1050-1057. doi: 10.1104/pp.111.174581

Soteras F, Renison D, Becerra AG (2013) Growth response, phosphorus content and root colonization of Polylepis australis Bitt. seedlings inoculated with different soil types. New For 44:577-589. doi: 10.1007/s11056-013-9364-X

Su Z-Z, Mao L-J, Li N, et al (2013) Evidence for biotrophic lifestyle and biocontrol potential of dark septate endophyte Harpophora oryzae to rice blast disease. PLoS One 8:e61332. doi: 10.1371/journal.pone.0061332

Takacs T, Voros I (2003) Effect of metal non-adapted arbuscular mycorrhizal fungi on Cd, Ni and Zn uptake by Ryegrass. Acta agranomica hungarica 51:347-354. doi: 10.1017/CBO9781107415324.004

Tellenbach C, Grünig CR, Sieber TN (2010) Suitability of quantitative real-time PCR to estimate the biomass of fungal root endophytes. Appl Environ Microbiol 76:5764-72. doi: 10.1128/AEM.00907-10

Thonar C, Erb A, Jansa J (2012) Real-time PCR to quantify composition of arbuscular mycorrhizal fungal communities-marker design, verification, calibration and field validation. Mol Ecol Resour 12:219-32. doi: $10.1111 / \mathrm{j} .1755-0998.2011 .03086 . x$

Tóth G, Hermann T, Da Silva MR, Montanarella L (2016) Heavy metals in agricultural soils of the European Union with implications for food safety. Environ Int 88:299-309. doi: 10.1016/j.envint.2015.12.017

Trouvelot A, Kough JL, Gianinazzi-Pearson V (1986) Mesure du taux de mycorhization VA d'un système radiculaire. Recherches et méthodes d'estimation ayant une signification fonctionnelle. In: Gianinazzi S, Gianinazzi-Pearson V (eds) Mycorhizes : physiologie et génétique. INRA, Dijon, pp 217-220 
Utmazian MNDS, Schweiger P, Sommer P, et al (2007) Influence of Cadophora finlandica and other microbial treatments on cadmium and zinc uptake in willows grown on polluted soil. Plant soil Environ 53:158-166.

Vági P, Knapp DG, Kósa A, et al (2014) Simultaneous specific in planta visualization of root-colonizing fungi using fluorescence in situ hybridization (FISH). Mycorrhiza 24:259-266. doi: 10.1007/s00572-013-0533-8

Vaz ABM, Sampedro I, Siles JA, et al (2012) Arbuscular mycorrhizal colonization of Sorghum vulgare in presence of root endophytic fungi of Myrtus communis. Appl Soil Ecol 61:288-294. doi: 10.1016/j.apsoil.2011.10.017

Wang J, Li T, Liu G, et al (2016) Unraveling the role of dark septate endophyte (DSE) colonizing maize (Zea mays) under cadmium stress: physiological, cytological and genic aspects. Nat Sci Reports 6:1-12. doi: $10.1038 /$ srep22028

Weissenhorn I, Glashoff A, Leyval C, Berthelin J (1994) Differential tolerance to Cd and Zn of arbuscular mycorrhizal (AM) fungal spores isolated from heavy metal-polluted and unpolluted soils. Plant Soil 167:189-196. doi: 10.1007/BF00007944

Whipps JM (2001) Microbial interactions and biocontrol in the rhizosphere. J Exp Bot 52:487-511. doi: 10.1093/jexbot/52.suppl_1.487

White C, Sayer JA, Gadd GM (1997) Microbial solubilization and immobilization of toxic metals: Key biogeochemical processes for treatment of contamination. FEMS Microbiol Rev 20:503-516. doi: 10.1016/S0168-6445(97)00029-6

Wright SF (2000) A fluorescent antibody assay for hyphae and glomalin from arbuscular mycorrhizal fungi. Plant Soil 226:171-177. doi: 10.1023/A:1026428300172

Zhan F, He Y, Li Y, et al (2015) Subcellular distribution and chemical forms of cadmium in a dark septate endophyte (DSE), Exophiala pisciphila. Environ Sci Pollut Res 22:17897-17905. doi: 10.1007/s11356015-5012-

\section{Figure captions}

Fig 1 Fungal colonization of ryegrass inoculated with $F$. mosseae (AMF), Cadophora sp. (DSE), or AMF+DSE

(a) and (b), Assessment of root colonization based on root colonization frequency (F\%) and intensity by hyphae 
(H\% for DSE and M\% for AMF), microsclerotia (MS\%), or arbuscules (A\%). (c) and (d), Assessment of root colonization based on real-time PCR analyses. Values are means \pm SEs $(n=6)$. Bars topped by the same letter do not differ significantly between inoculation treatments $(\mathrm{P}<0.05$, Kruskal-Wallis test).

Fig 2 Morphological characteristics of fungal structures in ryegrass roots

Trypan blue-stained roots were observed by optical microscopy (a and d), whereas WGA-AF488®-stained roots (b and c) were observed by confocal microscopy. Green: fungal material; red: autofluorescence of root cells. (a) and (d) show dual colonization by AMF hyphae in blue and DSE hyphae and microsclerotia in brown. Arbuscular structures can be seen in (b). Typical brain-like (a), loosely packed (c), and fully packed microsclerotia (d). Scale bars $=25 \mu \mathrm{m}$.

Fig 3 Effects of F. mosseae (AMF) and Cadophora sp. (DSE) inoculation on ryegrass growth and chlorophyll, malondialdehyde (MDA) and total antioxidant compound (TAC) concentrations.

(a) Black and hatched bars represent shoot and root dry weights, respectively, (b), (c) and (d) represent chlorophyll, MDA and TAC concentrations, respectively. Data are means \pm SEs $(n=6)$. Bars topped by the same letter do not differ significantly between treatments ( $\mathrm{P} \leq 0.05$, Kruskal-Wallis test).

Fig 4 Effects of F. mosseae (AMF) and Cadophora sp. (DSE) inoculation on soil enzyme activities

Fluoresceine diacetate (FDA) hydrolysis (a) and alkaline phosphatase (AP) activity (b) were determined in rhizosphere soils after plant harvest. Data are expressed as means \pm SEs $(n=9)$. Bars topped by the same letter do not differ significantly between treatments $(\mathrm{P} \leq 0.05$, Kruskal-Wallis test).

Table 1 Soil physico-chemical characteristics

\begin{tabular}{|c|c|c|c|c|c|c|c|c|c|c|c|c|}
\hline & $\mathrm{pH}$ & CEC & $\mathrm{P}_{2} \mathrm{O}_{5(\mathrm{~J}}$ & total $\mathrm{N}$ & total & $\mathrm{C} / \mathrm{N}$ & \multicolumn{3}{|c|}{ Fractions (\%) } & \multicolumn{2}{|l|}{ Trace } & element \\
\hline & $\mathrm{H} 2 \mathrm{O}$ & Metson & oret- & $(\mathrm{g} / \mathrm{kg})$ & $\mathrm{K}$ & & \multicolumn{6}{|c|}{ concentration } \\
\hline & & & Hebert) & & & & $0-2$ & $2-50$ & $50-$ & $\mathrm{Cd}$ & $\mathrm{Pb}$ & $\mathrm{Zn}$ \\
\hline Val & 7.4 & 82.0 & $1.1 \pm$ & 2.7 & 10.4 & 11.5 & $3.7 \pm$ & $10.5 \pm$ & $87.5 \pm$ & $1.5 \pm$ & 139 & $318 \pm$ \\
\hline
\end{tabular}


Values are means \pm SEs $(n=3)$.

Table 2 Effect of Cadophora sp. (DSE) and F. mosseae (AMF) inoculation on concentrations in trace and major elements in ryegrass shoots

\begin{tabular}{|c|c|c|c|c|c|c|}
\hline \multirow[t]{2}{*}{ Inoculum } & \multicolumn{6}{|c|}{ Shoot element concentrations (mg/kg DW) } \\
\hline & $\mathrm{Cd}$ & $\mathrm{K}$ & $\mathrm{Mg}$ & $\mathrm{Na}$ & $\mathrm{P}$ & $\mathrm{Zn}$ \\
\hline None & $1.3 \pm 0.1^{\mathrm{a}}$ & $17,323 \pm 333^{b}$ & $2,066 \pm 91^{\mathrm{ab}}$ & $2.1 \pm 0.2^{\mathrm{c}}$ & $2,009 \pm 94^{\mathrm{b}}$ & $120 \pm 11.1^{\mathrm{a}}$ \\
\hline $\mathrm{AMF}$ & $1.2 \pm 0.1^{\mathrm{ab}}$ & $19,110 \pm 442^{\mathrm{a}}$ & $2,341 \pm 102^{\mathrm{a}}$ & $3.3 \pm 0.1^{\mathrm{a}}$ & $2,323 \pm 80^{\mathrm{a}}$ & $97 \pm 7.5^{\mathrm{a}}$ \\
\hline $\mathrm{AMF}+\mathrm{DSE}$ & $1.1 \pm 0.1^{\mathrm{b}}$ & $17,645 \pm 296^{\mathrm{b}}$ & $2,046 \pm 45^{\mathrm{b}}$ & $2.1 \pm 0.2^{\mathrm{c}}$ & $1,832 \pm 75^{\mathrm{b}}$ & $116 \pm 8.5^{\mathrm{a}}$ \\
\hline DSE & $1.4 \pm 0.1^{\mathrm{a}}$ & $18,069 \pm 410^{\mathrm{ab}}$ & $2,023 \pm 89^{b}$ & $2.7 \pm 0.2^{\mathrm{b}}$ & $2,064 \pm 55^{\mathrm{b}}$ & $101 \pm 4.5^{\mathrm{a}}$ \\
\hline
\end{tabular}

Values are means \pm SEs $(n=9)$. Values with the same letter do not differ significantly between inoculation treatments $(\mathrm{P}<0.05$, Kruskal-Wallis test).

Table 3 Effect of Cadophora sp. (DSE) and F. mosseae (AMF) on the $\mathrm{CaCl}_{2}$-extractable fraction of soil trace and major elements

\begin{tabular}{lllllll}
\hline \multicolumn{7}{c}{ Available fraction $\left(\mathrm{CaCl}_{2}\right.$-extracted $)$} \\
\cline { 2 - 6 } & $\mathrm{Cd}(\mu \mathrm{g} / \mathrm{kg}$ soil $)$ & $\mathrm{K}(\mathrm{mg} / \mathrm{kg}$ soil $)$ & $\mathrm{Mg}(\mathrm{mg} / \mathrm{kg}$ soil $)$ & $\mathrm{Na}(\mathrm{mg} / \mathrm{kg}$ soil $)$ & $\mathrm{P}(\mathrm{mg} / \mathrm{kg} \mathrm{soil})$ & $\mathrm{Z}$ \\
\hline none & $44.0 \pm 1.1^{\mathrm{a}}$ & $18.1 \pm 3.8^{\mathrm{b}}$ & $140.4 \pm 3.2^{\mathrm{a}}$ & $123.5 \pm 8.2^{\mathrm{a}}$ & $22.9 \pm 1.4^{\mathrm{ab}}$ & 3 \\
AMF & $51.3 \pm 2.1^{\mathrm{a}}$ & $25.7 \pm 4.2^{\mathrm{a}}$ & $136.7 \pm 3.5^{\mathrm{a}}$ & $141.9 \pm 2.6^{\mathrm{a}}$ & $23.6 \pm 0.4^{\mathrm{a}}$ & 3 \\
AMF+DSE & $40.6 \pm 1.9^{\mathrm{a}}$ & $19.2 \pm 1.3^{\mathrm{ab}}$ & $137.6 \pm 3.0^{\mathrm{a}}$ & $125.0 \pm 13.6^{\mathrm{a}}$ & $22.7 \pm 0.2^{\mathrm{b}}$ & 2 \\
DSE & $41.5 \pm 1.9^{\mathrm{a}}$ & $12.9 \pm 0.2^{\mathrm{c}}$ & $137.7 \pm 3.7^{\mathrm{a}}$ & $109.1 \pm 9.8^{\mathrm{a}}$ & $21.2^{2} \pm 0.2^{\mathrm{b}}$ & 2 \\
\hline
\end{tabular}

Values are means \pm SEs $(n=9)$. Values with the same letter do not differ significantly between inoculation treatments $(\mathrm{P}<0.05$, Kruskal-Wallis test $)$ 
a

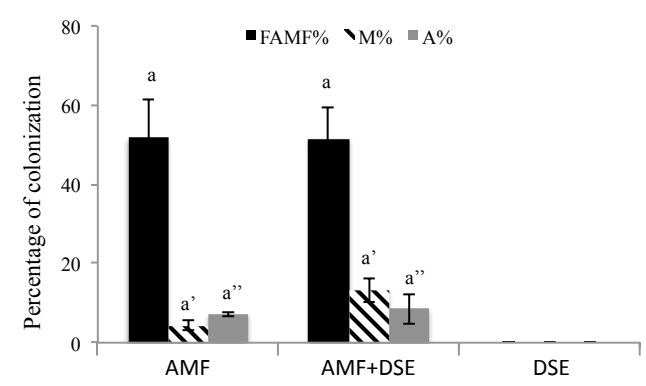

c

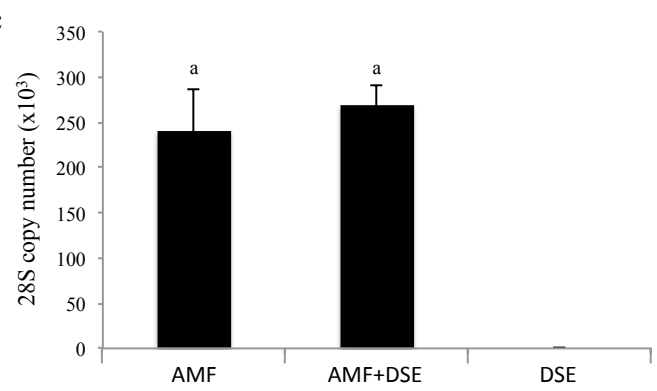

b
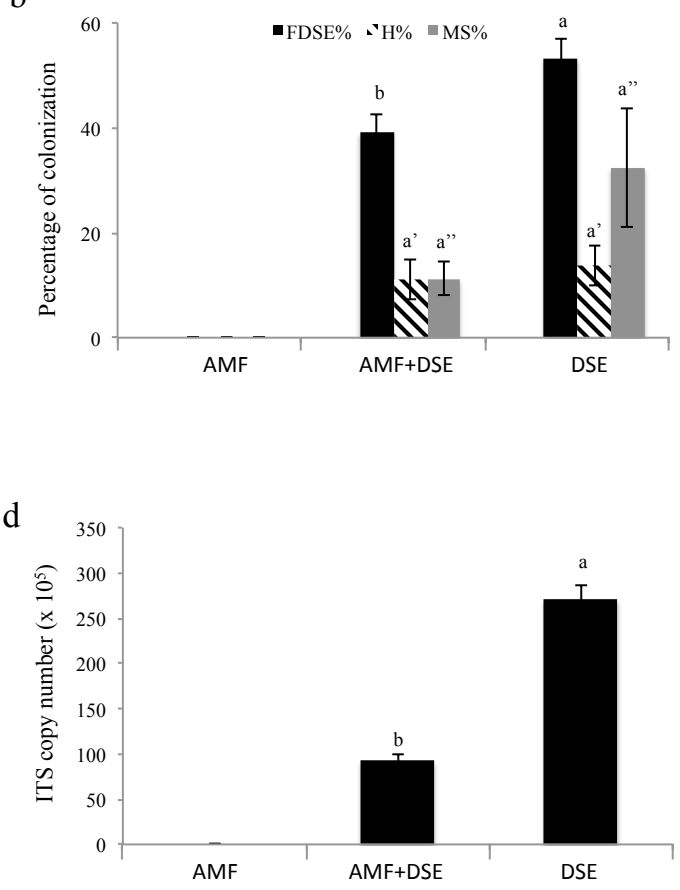

Fig 1 

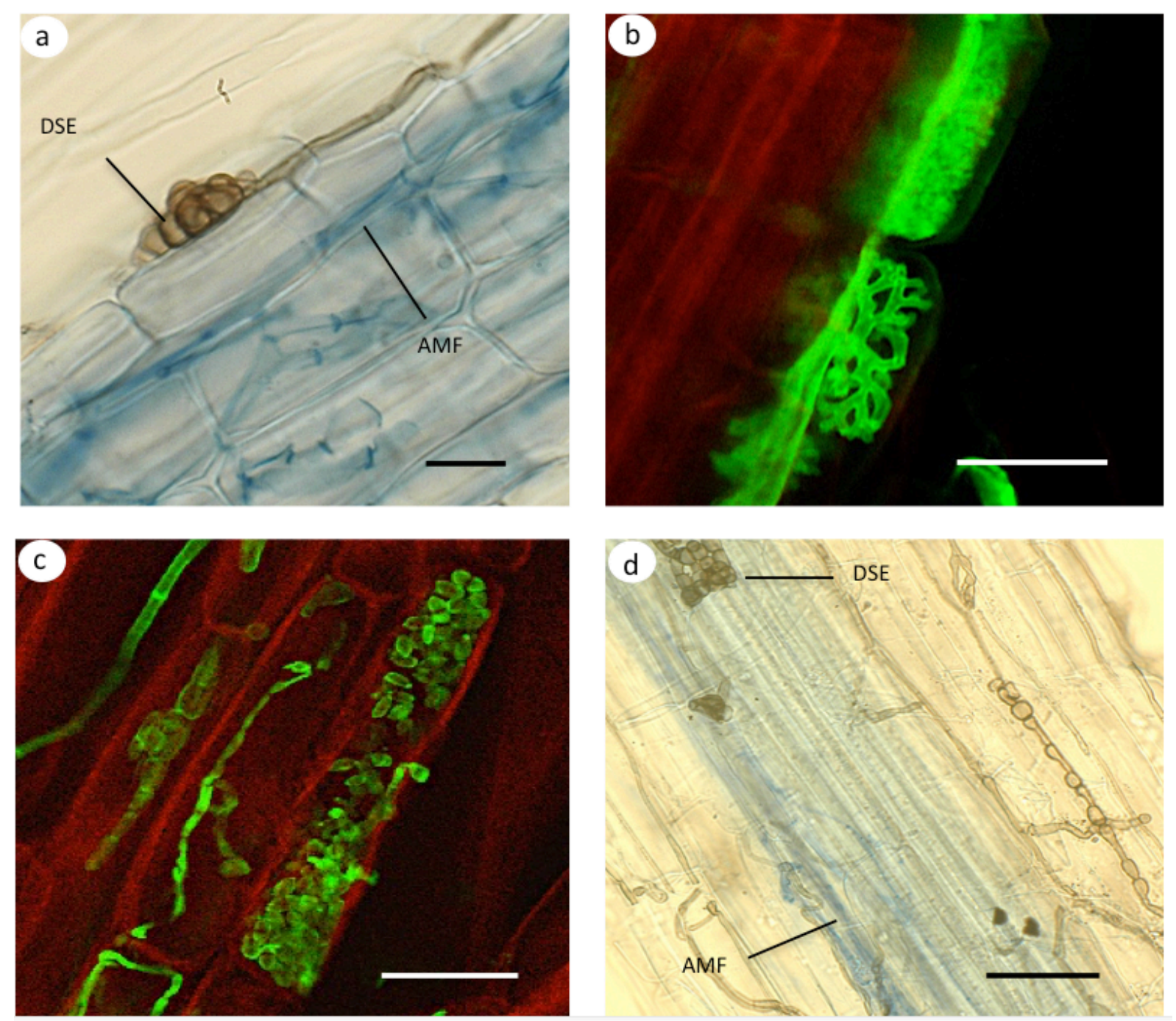

Fig. 2 

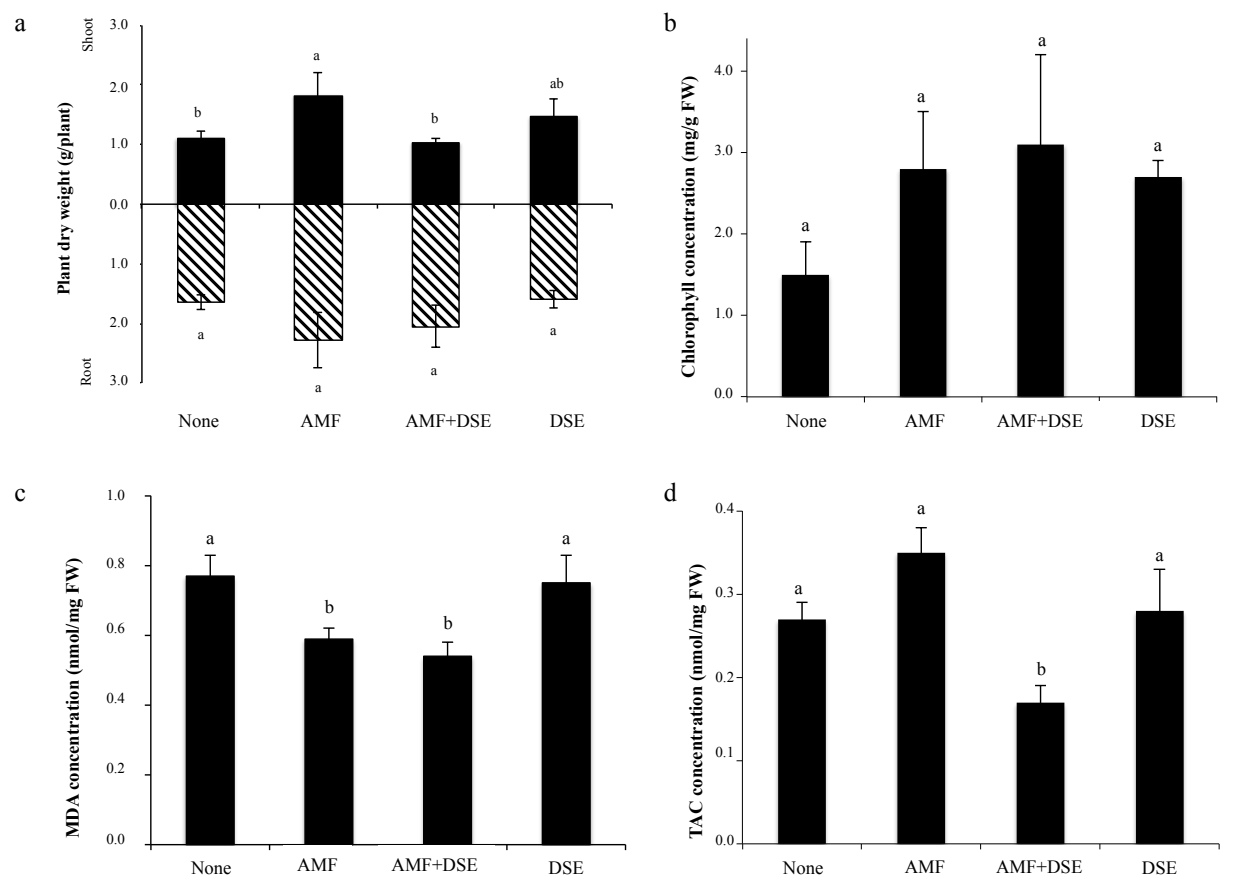

Fig 3 

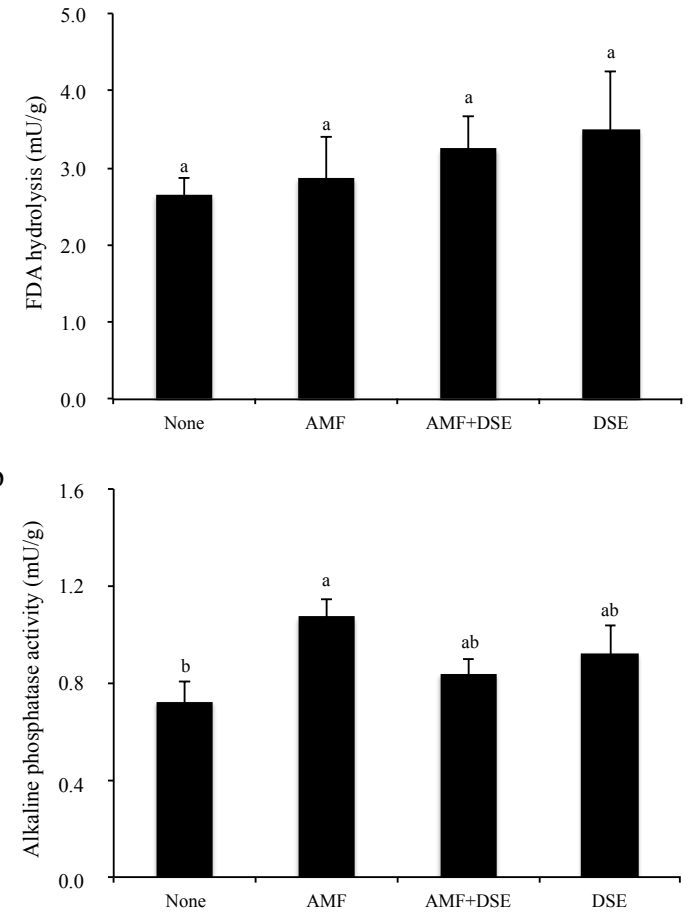

Fig 4 

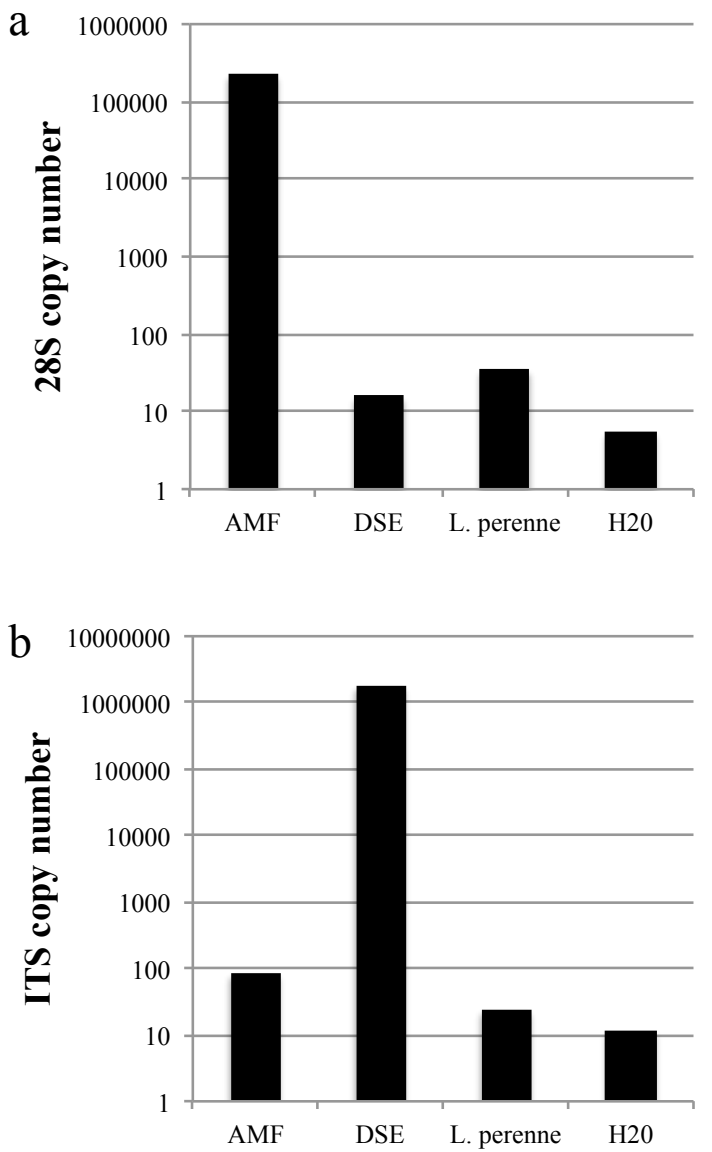

Fig S1 Tests of cross-specify of qPCR primers with genomic DNA from $F$. mosseae (AMF), Cadophora sp. (DSE) and roots of L. perenne

Assessment of qPCR amplifications with primers for AMF (a) and DSE (b). Negative controls were performed using sterile distilled water. 